\section{Chronic Hypercapnia Stimulates Proximal Bicarbonate Reabsorption in the Rat}

\author{
Martin G. Cogan \\ Cardiovascular Research Institute and Department of Medicine, \\ University of California, San Francisco, California 94143
}

glomerular filtration might fall as the plasma bicarbonate concentration rises, thus attenuating or preventing the increase in filtered bicarbonate load. Relatively normal rates of tubular hydrogen ion secretion would then suffice to prevent bicarbonate from appearing in the urine. This mechanism has been proposed to be the one that maintains the other major hyperbicarbonatemic acid-base disorder, chronic metabolic alkalosis (1). On the other hand, if glomerular filtration remained normal, enhanced tubular bicarbonate reabsorption, predominantly in the proximal nephron, would be needed to prevent bicarbonaturia.

Measurement of absolute rates of bicarbonate filtration and proximal reabsorption needed to differentiate these two pathophysiological mechanisms have not been reported to date. In previous free-flow micropuncture studies fractional proximal bicarbonate reabsorption in chronic hypercapnia appeared normal, a finding that does not allow discrimination between the two alternatives (2). Split-droplet studies during chronic hypercapnia have found a relatively normal rate of proximal acidification (3), which would support the first process discussed above (reduced filtration rate with normal bicarbonate reabsorption). Acute hypercapnia has also been found to have only a small effect on free-flow proximal bicarbonate reabsorption (4). In fact, no factor has yet been reported to reliably increase proximal bicarbonate reabsorption above the mean level found in the normal euvolemic state $(1,5)$.

Thus, the purpose of the present studies was to measure absolute rates of bicarbonate filtration and reabsorption in rats rendered chronically hypercapnic.

\section{Methods}

Protocols. To induce chronic respiratory acidosis, 12 Munich-Wistar rats were exposed to $10 \% \mathrm{CO}_{2}$ (air balance) in an environmental chamber for 6-8 d. Gas samples from the chamber were periodically measured to ensure that the $10 \% \mathrm{CO}_{2}$ atmosphere was constant. Rats were allowed chow diet and distilled water ad lib. while in the chamber. On the day of micropuncture study, the animal was rapidly weighed (mean weight was $184 \pm 4 \mathrm{~g}$ ), injected intraperitoneally with Inactin $(100 \mathrm{mg} / \mathrm{kg})$, and immediately placed into a holding chamber flooded with the same $10 \% \mathrm{CO}_{2}$ gas mixture. When anesthetized, the rat was removed from the holding chamber, a tracheostomy and intubation were performed as rapidly as possible $(\leq 2 \mathrm{~min})$, and $10 \% \mathrm{CO}_{2}$ was again administered via a T-tube apparatus, as previously described (4). 
The rest of the surgical preparation and free-flow micropuncture techniques were performed as previously outlined (5). Surgically induced plasma volume losses, assumed to be similar to previously established values (1.3\% body weight), and whole blood losses from sampling were quantitatively replaced (5). Donors for plasma and whole blood were also maintained in the environmental chamber with $10 \% \mathrm{CO}_{2}$ for 6-8 d.

After the first period of micropuncture, eight animals were extubated and allowed to breathe room air to allow arterial partial pressure of $\mathrm{CO}_{2}\left(\mathrm{pCO}_{2}\right)^{1}$ to decrease toward normal. After a 30-60-min equilibration, the animals were again studied by micropuncture during this post-hypercapnic period. The time between extubation and the end of the second micropuncture period was $\sim 1-1.5 \mathrm{~h}$.

A separate group of 15 animals was rendered acutely alkalotic to serve as normocapnic controls for the post-hypercapnic animals. A $10 \%$ body weight bicarbonate solution $\left(\mathrm{NaHCO}_{3} 200 \mathrm{mM}\right.$ plus $\mathrm{KCl}$ $25 \mathrm{mM}$ ) was infused over $1 \mathrm{~h}$, and followed by a maintenance infusion of $0.1 \mathrm{ml} / \mathrm{min}$. Micropuncture began after an equilibration of $30 \mathrm{~min}$. Tubular chloride concentrations were not measured in this group.

Analysis and calculations. Plasma, urine, and tubular fluid measurements were made as previously described $(1,4,5) .\left[{ }^{3} \mathrm{H}\right]$ inulin was measured by scintillation counting, total $\mathrm{CO}_{2}$ by microcalorimetry (6), and chloride by the method of Ramsay (7). Calculations of filtration and reabsorptive rates were also as previous outlined $(1,4,5)$. Results are presented as mean \pm SEM, and significance was assessed by the paired or unpaired $t$ test as appropriate.

\section{Results}

Exposure to $10 \% \mathrm{CO}_{2}$ for $6-8 \mathrm{~d}$ resulted in chronic respiratory acidosis. Arterial measurements were: $\mathrm{pH} 7.30 \pm 0.01 ; \mathrm{pCO}_{2}$, $80 \pm 2 \mathrm{mmHg}$; plasma total $\mathrm{CO}_{2}$ concentration, $45 \pm 1 \mathrm{mM}$; and plasma chloride concentration, $93 \pm 1 \mathrm{meq} / \mathrm{liter}$. Other blood measurements and urinary excretion data, shown in Table I, were generally similar to those previously reported for normal euvolemic rats $(5,8)$. Kidney weight was $0.90 \pm 0.04 \mathrm{~g}$.

Micropuncture results are shown in Table II. Single nephron glomerular filtration rate (SNGFR) $(42.4 \pm 0.7 \mathrm{nl} / \mathrm{min})$ was normal for rats of this size $(5,8)$. The elevated total $\mathrm{CO}_{2}$ concentration in Bowman's space $(47.9 \pm 0.9 \mathrm{mM})$ was therefore associated with a high filtered total $\mathrm{CO}_{2}$ load $(2,025 \pm 47 \mathrm{pmol} /$ min). Chronic hypercapnia caused absolute proximal total $\mathrm{CO}_{2}$ reabsorption to be stimulated to $1,449 \pm 26 \mathrm{pmol} / \mathrm{min}$, a value $35 \%$ higher than that of a normal euvolemic animal (1,075 $\pm 74 \mathrm{pmol} / \mathrm{min}, P<0.001)$ (5).

Bicarbonate reabsorption during chronic hypercapnia was also higher than values previously reported after acute exposure to $10 \% \mathrm{CO}_{2}$ (4). The comparison of micropuncture data during chronic and acute hypercapnia is shown in Table III. In chronic hypercapnia, total $\mathrm{CO}_{2}$ reabsorption was $23 \%$ higher than when acute hypercapnia was superimposed on chronic metabolic alkalosis, despite there being only a slight difference

1. Abbreviations used in this paper: $\mathrm{pCO}_{2}$, partial pressure of $\mathrm{CO}_{2}$; SNGFR, single nephron glomerular filtration rate.
Table I. Blood Composition and Urinary Excretion Rates in Chronic Hypercapnia and Post-Hypercapnia

\begin{tabular}{|c|c|c|c|}
\hline & $\begin{array}{l}\text { Chronic } \\
\text { hypercapnia }\end{array}$ & $\begin{array}{l}\text { Post- } \\
\text { hypercapnia }\end{array}$ & $P$ \\
\hline \multicolumn{4}{|l|}{ Blood } \\
\hline \multicolumn{4}{|l|}{ Arterial } \\
\hline pH & $7.30 \pm 0.01$ & $7.50 \pm 0.01$ & $<0.001$ \\
\hline $\mathrm{pCO}_{2}(\mathrm{mmHg})$ & $80 \pm 2$ & $46 \pm 1$ & $<0.001$ \\
\hline Blood pressure $(\mathrm{mmHg})$ & $130 \pm 4$ & $114 \pm 3$ & $<0.005$ \\
\hline Hematocrit (vol \%) & $47.5 \pm 0.7$ & $46.5 \pm 0.5$ & $<0.025$ \\
\hline \multicolumn{4}{|l|}{ Plasma } \\
\hline$\left[\mathrm{Na}^{+}\right]$(meq/liter) & $149 \pm 1$ & $146 \pm 1$ & $<0.01$ \\
\hline$\left[\mathrm{K}^{+}\right]$(meq/liter) & $3.9 \pm 0.1$ & $3.9 \pm 0.1$ & NS \\
\hline [Total $\left.\mathrm{CO}_{2}\right](m M)$ & $45 \pm 1$ & $37 \pm 1$ & $<0.001$ \\
\hline$\left[\mathrm{Cl}^{-}\right]$(meq/liter) & $93 \pm 1$ & $96 \pm 1$ & $<0.05$ \\
\hline [Protein] $(g / d l)$ & $5.2 \pm 0.1$ & $5.0 \pm 0.1$ & $<0.25$ \\
\hline \multicolumn{4}{|l|}{ Urine } \\
\hline $\begin{array}{l}\text { Glomerular filtration rate } \\
\qquad(\mathrm{ml} / \mathrm{min} \cdot g k w t)\end{array}$ & $1.0 \pm 0.1$ & $1.0 \pm 0.1$ & NS \\
\hline \multicolumn{4}{|l|}{ Urinary excretion } \\
\hline $\mathrm{Na}^{+}(\mu e q / \min )$ & $0.2 \pm 0.1$ & $0.2 \pm 0.1$ & NS \\
\hline $\mathrm{K}^{+}(\mu \mathrm{eq} / \mathrm{min})$ & $0.5 \pm 0.1$ & $1.0 \pm 0.1$ & $<0.01$ \\
\hline Total $\mathrm{CO}_{2}(\mu \mathrm{mol} / \mathrm{min})$ & $0.05 \pm 0.02$ & $0.4 \pm 0.1$ & $<0.05$ \\
\hline $\mathrm{Cl}^{-}(\mu e q / \min )$ & $0.5 \pm 0.1$ & $1.0 \pm 0.4$ & NS \\
\hline Volume $(\mu l / m i n)$ & $2.9 \pm 0.4$ & $2.4 \pm 0.2$ & NS \\
\hline
\end{tabular}

kwt, kidney weight; NS, not significant.

in the logarithmic mean luminal total $\mathrm{CO}_{2}$ concentration, an important determinant of proximal acidification $(5,9,10)$. Total $\mathrm{CO}_{2}$ reabsorption was also $21 \%$ higher during chronic hypercapnia than when acute hypercapnia was superimposed on acute metabolic alkalosis. In this case, the acutely hypercapnic group had a higher SNGFR and mean luminal total $\mathrm{CO}_{2}$ concentration, factors which, if anything, should accelerate acidification $(9,10)$. The stimulation of bicarbonate reabsorption over mean normal levels in the chronically hypercapnic group but not in the combined acutely hypercapnic groups is illustrated in Fig. 1.

Absolute chloride reabsorption during chronic respiratory acidosis (Table II) was slightly reduced from normal values, possibly as a result of the hypochloremic state (1), whereas absolute water reabsorption was approximately the same as in normal euvolemic animals $(5,8)$.

When eight of the animals were extubated and allowed to breathe room air, a stable post-hypercapnic metabolic alkalosis developed, with arterial $\mathrm{pH}$ of $7.50 \pm 0.01$ and $\mathrm{pCO}_{2}$ of $46 \pm 1$ $\mathrm{mmHg}$ (Table I). Plasma total $\mathrm{CO}_{2}$ concentration fell to $37 \pm 1$ $\mathrm{mM}$, associated with bicarbonaturia. SNGFR was stable (Table II). The resulting decline in filtered total $\mathrm{CO}_{2}$ load $(1,665 \pm 68$ $\mathrm{pmol} / \mathrm{min}$ ) was associated with a fall in absolute proximal total $\mathrm{CO}_{2}$ reabsorption to $1,211 \pm 34 \mathrm{pmol} / \mathrm{min}$. However, this 


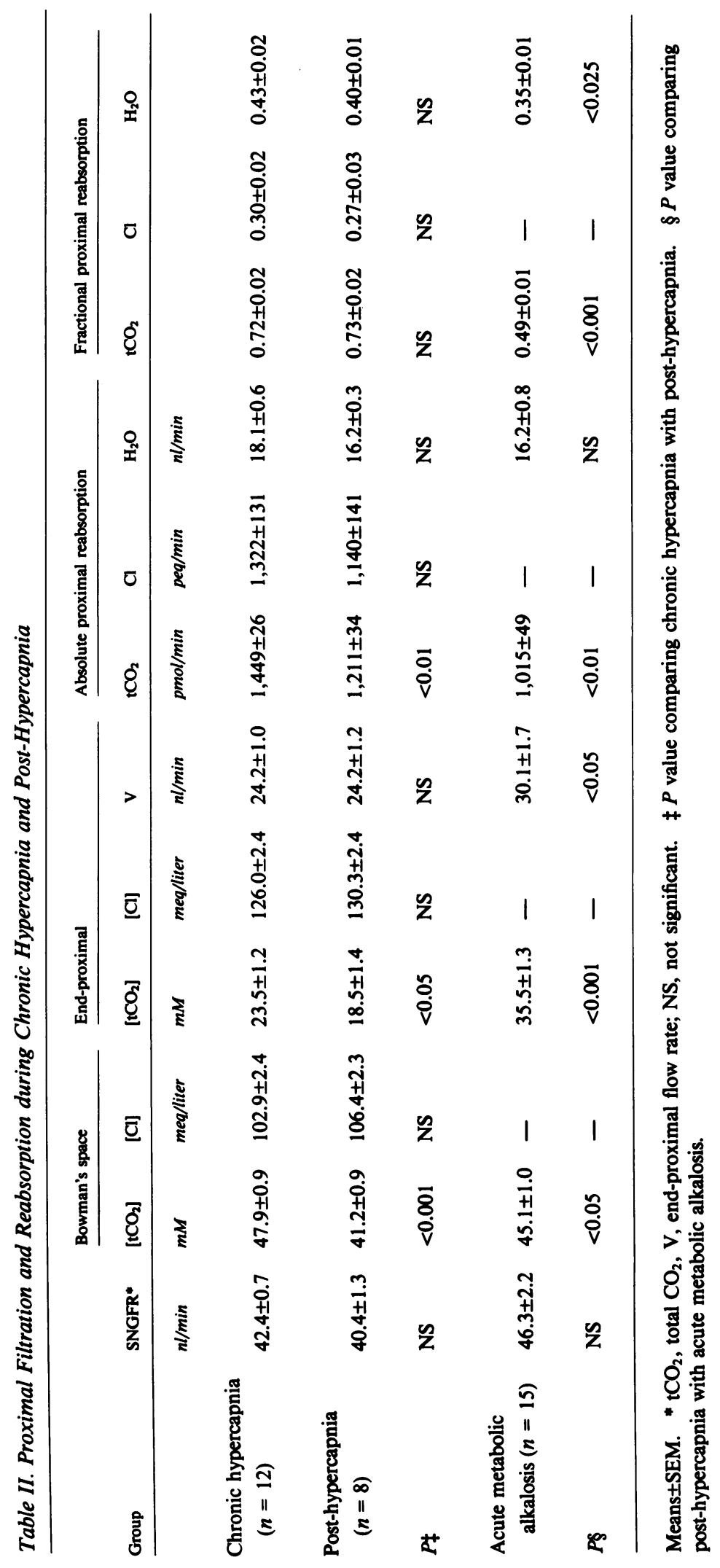


Table III. Proximal Bicarbonate Reabsorption during Hypercapnic States

\begin{tabular}{|c|c|c|c|c|c|c|}
\hline Group & $\begin{array}{l}\text { Bowman's } \\
\text { space } \\
\text { [total } \mathrm{CO}_{2} \text { ] }\end{array}$ & SNGFR & $\begin{array}{l}\text { Filtered total } \\
\mathrm{CO}_{2} \text { load }\end{array}$ & $\begin{array}{l}\text { End- } \\
\text { proximal } \\
\text { [total } \mathrm{CO}_{2} \text { ] }\end{array}$ & $\begin{array}{l}\text { Log mean } \\
\text { [total } \mathrm{CO}_{2} \text { ] }\end{array}$ & $\begin{array}{l}\text { Absolute } \\
\text { proximal } \\
\text { total } \mathrm{CO}_{2} \\
\text { reabsorption }\end{array}$ \\
\hline & $m M$ & $n l / m i n$ & $\mathrm{pmol} / \mathrm{min}$ & $m M$ & $m M$ & $\mathrm{pmol} / \mathrm{min}$ \\
\hline Chronic hypercapnia $(n=12)$ & $47.9 \pm 0.9$ & $42.4 \pm 0.7$ & $2,025 \pm 47$ & $23.5 \pm 1.2$ & $34 \pm 1$ & $1,449 \pm 26$ \\
\hline \multicolumn{7}{|l|}{ Acute hypercapnia* } \\
\hline+ chronic metabolic alkalosis $(n=10)$ & $50.4 \pm 1.7$ & $27.9 \pm 1.7$ & $1,385 \pm 98$ & $15.5 \pm 1.1$ & $30 \pm 1$ & $1,176 \pm 77$ \\
\hline$P \ddagger$ & NS & $<0.001$ & $<0.001$ & $<0.001$ & $<0.05$ & $<0.005$ \\
\hline+ Acute metabolic alkalosis $(n=7)$ & $58.6 \pm 1.5$ & $50.1 \pm 1.5$ & $2,951 \pm 249$ & $49.0 \pm 1.5$ & $54 \pm 1$ & $1,234 \pm 97$ \\
\hline$P \ddagger$ & $<0.001$ & $<0.025$ & $<0.001$ & $<0.001$ & $<0.001$ & $<0.025$ \\
\hline
\end{tabular}

* From reference 4. $¥$ As compared with chronic hypercapnia.

value for total $\mathrm{CO}_{2}$ reabsorption in the post-hypercapnic period was still significantly higher than in a previous report on a group of 22 animals with chronic metabolic alkalosis $(981 \pm 49$ $\mathrm{pmol} / \mathrm{min}, P<0.025$ ) that had both a similar arterial $\mathrm{pCO}_{2}$ $(43 \pm 1 \mathrm{mmHg})$ and a mean luminal total $\mathrm{CO}_{2}$ concentration (32 mM) (1). The post-hypercapnic value was also higher than in the 15 animals in this study with acute metabolic alkalosis $(1,015 \pm 49 \mathrm{pmol} / \mathrm{min}, P<0.01)$, as shown in Table II. This

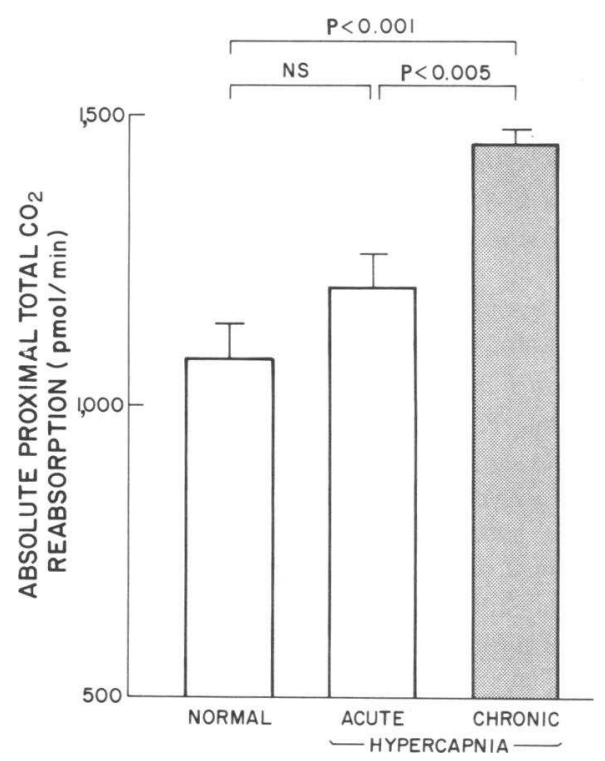

Figure 1. Comparison of absolute proximal bicarbonate reabsorption in rats with chronic hypercapnia with reabsorption in normal euvolemic rats (from reference 5) and with reabsorption in combined groups of rats with acute hypercapnia superimposed on chronic or acute metabolic alkalosis (from reference 4). latter group had a slightly lower arterial $\mathrm{pCO}_{2}(39 \pm 1 \mathrm{mmHg})$ but a higher SNGFR $(46 \pm 2 \mathrm{nl} / \mathrm{min})$ and mean luminal total $\mathrm{CO}_{2}$ concentration $(40 \mathrm{mM})$. Thus, as illustrated in Fig. 2, stimulation of proximal bicarbonate reabsorption by chronic hypercapnia appeared to persist, at least to some degree, after inhalation of $\mathrm{CO}_{2}$ was terminated.

\section{Discussion}

It has long been known that several days are required for the full increase in renal bicarbonate reabsorption due to a sustained

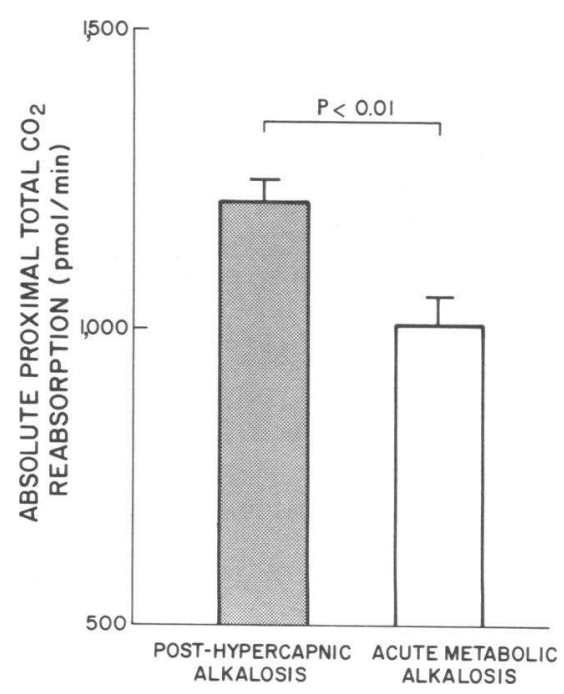

Figure 2. Comparison of absolute proximal bicarbonate reabsorption in rats with post-hypercapnic alkalosis with reabsorption in rats with acute metabolic alkalosis (no pre-existing hypercapnic stimulus). 
increment in arterial $\mathrm{pCO}_{2}(11)$, irrespective of sodium intake (12), bicarbonate availability and rate of net acid excretion (13), potassium stores (14), or mineralocorticoid activity (15). The present studies demonstrate that this renal adaptive response is mediated not by altered hemodynamics (i.e., by a reduction in glomerular filtration rate) but rather by increased bicarbonate transport in the superficial proximal convoluted tubule. A simultaneous adaptation in bicarbonate reabsorption by sites distal to the superficial proximal convoluted tubule and/or by juxtamedullary nephrons is also possible. That such nephron segments contribute to the adaptive response is supported by the finding that when the arterial $\mathrm{pCO}_{2}$ was allowed to return toward normal in the second period, bicarbonaturia appeared despite the fact that bicarbonate delivery out of the superficial proximal tubule was lower ( $454 \pm 46$ post-hypercapnia as compared with $577 \pm 45 \mathrm{pmol} / \mathrm{min}$ during chronic hypercapnia).

The mechanism underlying this stimulation of proximal bicarbonate reabsorption during chronic hypercapnia might involve either a primary increase in $\mathrm{Na}^{+} / \mathrm{H}^{+}$exchanger activity and/or in bicarbonate exit. Rector has argued for the former based on the time course of changes in ammonium excretion induced by hypercapnia (16). An increase in antiporter activity caused by chronic metabolic acidosis has been recently demonstrated (17-19). Studies using vesicle preparations or intracellular microelectrodes will be necessary to clarify whether a similar mechanism is induced by chronic respiratory acidosis.

The augmentation of proximal bicarbonate reabsorption persisted, to some degree, for as long as $1.5 \mathrm{~h}$ after the discontinuation of $\mathrm{CO}_{2}$ inhalation. The possibility that cellular transport processes might have a "memory" of pre-existing conditions has been previously proposed for acidification in the distal tubule after hypocapnia (20), metabolic acid-base disturbances (21), or dietary manipulations (22). Changes in glycodiazine transport after acid-base disorders (3) and in volume adsorption measured in vitro after partial renal ablation in vivo (23) have also been documented in the proximal convoluted tubule. Such a memory effect in the proximal tubule after normalization of a high $\mathrm{CO}_{2}$ tension might be at least partially responsible for maintaining post-hypercapnic metabolic alkalosis, previously attributed solely to extracellular volume depletion (13).

In conclusion, chronic but not acute hypercapnia increased absolute proximal bicarbonate reabsorption. This is the first demonstration that proximal bicarbonate reabsorption can be stimulated above the mean level found in a normal, euvolemic animal.

\section{Acknowledgments}

I wish to thank Dr. Edmond I. Eger and Mr. Brynte H. Johnson for the generous loan of the environmental chamber, Mr. Kenneth Wong for excellent technical assistance, and Dr. Floyd C. Rector, Jr. for ongoing support and advice.

These studies were supported in part by a Clinical Investigator Award (1 KO8 AM-01015) and a grant (AM-27045) from the National Institute of Arthritis, Diabetes, and Digestive and Kidney Diseases.

\section{References}

1. Cogan, M. G., and F.-Y. Liu. 1983. Metabolic alkalosis in the rat. Evidence that reduced glomerular filtration rather than enhanced tubular bicarbonate reabsorption is responsible for maintaining the alkalotic state. J. Clin. Invest. 71:1141-1160.

2. Warren, Y., R. G. Luke, M. Kashgarian, and H. Levitin. 1970. Micropuncture studies of chloride and bicarbonate absorption in the proximal renal tubule of the rat in respiratory acidosis and in chloride depletion. Clin. Sci. 38:375-383.

3. Ullrich, K. J., G. Rumrich, and K. Baumann. 1975. Renal proximal tubular buffer-(glycodiazine) transport. Inhomogeneity of local transport rate, dependence on sodium, effect of inhibitors and chronic adaptation. Pfluegers Arch. 357:149-163.

4. Cogan, M. G. 1984. Effects of acute alterations in $\mathrm{pCO}_{2}$ on proximal $\mathrm{HCO}_{3}^{-}, \mathrm{Cl}^{-}$and $\mathrm{H}_{2} \mathrm{O}$ reabsorption. Am. J. Physiol. (Renal Fluid and Electrolyte Physiol. 15). 246:F21-F26.

5. Cogan, M. G., D. A. Maddox, M. S. Lucci, and F. C. Rector, Jr. 1979. Control of proximal bicarbonate reabsorption in normal and acidotic rats. J. Clin. Invest. 64:1168-1180.

6. Vurek, G. G., D. G. Warnock, and R. Corsey. 1975. Measurement of picomole amounts of carbon dioxide by calorimetry. Anal. Chem. 47:765-767.

7. Ramsay, J. A., R. H. J. Brown, and P. C. Croghan. 1955. Electrometric titration of chloride in small volumes. J. Exp. Biol. 32:822-829.

8. Cogan, M. G. 1983 . Volume expansion predominantly inhibits proximal reabsorption of $\mathrm{NaCl}$ rather than $\mathrm{NaHCO}_{3}$. Am. J. Physiol. (Renal Fluid Electrolyte Physiol.). 245:F272-F275.

9. Cogan, M. G., and R. J. Alpern. 1984. Regulation of proximal bicarbonate reabsorption. Am. J. Physiol. (Renal Fluid and Electrolyte Physiol.), 247:F387-F395.

10. Alpern, R. J., M. G. Cogan, and F. C. Rector, Jr. 1982. Effect of luminal bicarbonite concentration on proximal acidification in the rat. Am. J. Physiol. (Renal Fluid Electrolyte Physiol.) 243:F53-F59.

11. Sullivan, W. J., and P. J. Dorman. 1955. The renal response to chronic respiratory acidosis. J. Clin. Invest. 34:268-276.

12. Polak, A., G. D. Haynie, R. M. Hays, and W. B. Schwartz. 1961. Effects of chronic hypercapnia on electrolyte and acid-base equilibrium. I. Adaptation. J. Clin. Invest. 40:1223-1237.

13. Van Ypersele de Strihou, C., P. F. Gulyassy, and W. B. Schwartz. 1962. Effects of chronic hypercapnia on electrolyte and acidbase equilibrium. III. Characteristics of the adaptive and recovery process as evaluated by provision of alkali. J. Clin. Invest. 41:22462253.

14. Makoff, D., and B. J. Rosenbaum. 1971. Adaptation to chronic hypercapnia in the potassium-depleted dog. Am. J. Physiol. 220:17241727.

15. Luke, R. G., and H. Levitin. 1966. The renal and electrolyte 
response to respiratory acidosis in the adrenalectomized rat. Yale $J$. Biol. Med. 39:27-37.

16. Rector, F. C., Jr. 1965. Role of the kidney in the homeostatic control of hydrogen ion concentration in body fluids. Excerpta Medical Int. Congr. Ser. 87:176-188.

17. Cohn, D. W., S. Klahr, and M. R. Hammerman. 1983. Metabolic acidosis and parathyroidectomy increase $\mathrm{Na}^{+} / \mathrm{H}^{+}$exchange in brush border vesicles. Am. J. Physiol. (Renal Fluid Electrolyte Physiol.). 245:F217-F222.

18. Kinsella, J. L., T. Cujkid, and B. Sacktor. 1984. $\mathrm{Na}^{+}-\mathrm{H}^{+}$ exchange activity in renal brush border membrane vesicles in response to metabolic acidosis: the role of glucocorticoids. Proc. Natl. Acad. Sci. USA. 81:630-634.

19. Tsai, C.-J., H. E. Ives, R. J. Alpern, V. J. Yee, D. G. Warnock, and F. C. Rector, Jr. 1984. Increased $V_{\max }$ for $\mathrm{Na}^{+} / \mathrm{H}^{+}$antiporter activity in proximal tubule brush border vesicles from rabbits with metabolic acidosis. Am. J. Physiol. (Renal Fluid Electrolyte Physiol.). 247:F339-F343.

20. Battle, D. C., K. Itsarayoungyuen, M. Downer, R. Foley, J. A. L. Arruda, and N. A. Kurtzman. 1983. Suppression of distal urinary acidification after recovery from chronic hypocapnia. Am. J. Physiol. (Renal Fluid Electrolyte Physiol.). 245:F433-F442.

21. Ullrich, K. J., and F. Papavassiliou. 1981. Bicarbonate reabsorption in the papillary collecting duct of rats. Pfluegers Arch. 389:271-275.

22. McKinney, T. D., and M. B. Burg. 1977. Bicarbonate transport by rabbit cortical collecting tubules. Effect of acid and alkali loads in vivo on transport in vitro. J. Clin. Invest. 60:766-768.

23. Trizna, W., N. Yanagawa, Y. Bar-Khayim, B. Houston, and L. G. Fine. 1981. Functional profile of the uremic nephron. Evidence of proximal tubular "memory" in experimental renal disease. J. Clin. Invest. 68:760-767. 